\title{
Status Asthmaticus
}

National Cancer Institute

\section{Source}

National Cancer Institute. Status Asthmaticus. NCI Thesaurus. Code C122577.

An acute exacerbation of asthma, characterized by inadequate response to initial bronchodilators. 